\title{
Efficacy of Ginkgolide B in the prophylaxis of migraine with aura
}

\author{
Giovanni D'Andrea · Gennaro Bussone · Gianni Allais • Marco Aguggia • \\ Florindo D'Onofrio - Maurizio Maggio - Franca Moschiano - Maria Gabriella Saracco • \\ Maria Grazia Terzi $\cdot$ Vittorio Petretta $\cdot$ Chiara Benedetto
}

(C) The Author(s) 2009. This article is published with open access at Springerlink.com

\begin{abstract}
In a multicentric, open, preliminary trial, we evaluated the use of ginkgolide $\mathrm{B}$, a herbal constituent extract from Ginkgo biloba tree leaves, in the prophylactic treatment of migraine with aura (MA). Fifty women suffering from migraine with typical aura, or migraine aura without headache, diagnosed according to International Headache Society criteria, entered a six-month study. They underwent a two month run-in period free of prophylactic drugs, followed by a four month treatment period (subdivided into two bimesters, TI and TII) with a combination of $60 \mathrm{mg}$ ginkgo biloba terpenes phytosome, $11 \mathrm{mg}$ coenzyme Q 10 , and $8.7 \mathrm{mg}$ vitamin B2 $\left(\right.$ Migrasoll $\left.^{\circledR}\right)$, administered
\end{abstract}

G. D'Andrea $(\bowtie)$

Headache and Cerebrovascular Center, Villa Margherita

Neurology Clinic, Arcugnano 36057 Vicenza, Italy

e-mail: giovidavi@virgilio.it

G. Bussone

C. Besta National Neurological Institute, Milan, Italy

G. Allais - M. G. Terzi - C. Benedetto

Women's Headache Center, Department of Gynecology

and Obstetrics, University of Turin, Turin, Italy

\section{Aguggia}

Department of Neurology, Novi Ligure Hospital,

Novi Ligure, Italy

F. D'Onofrio - V. Petretta

Department of Neurology, Moscati Hospital, Avellino, Italy

M. Maggio

Department of Neurology, Ivrea Hospital, Ivrea, Italy

F. Moschiano

Department of Neurology, SL Mandic Hospital, Merate, Italy

M. G. Saracco

Department of Neurology, Asti Hospital, Asti, Italy twice daily. A detailed diary reporting neurological symptoms, duration, and frequency of MA was compiled by patients throughout the trial. The number of MA significantly decreased during treatment (from $3.7 \pm 2.2$ in the run-in period, to $2.0 \pm 1.9$ during TI and to $1.2 \pm 1.6$ during TII; Anova for repeated measures: $P<0.0001$ ). There was also a statistically significant decrease in the average MA duration, which was $40.4 \pm 19.4$ min during run-in, $28.2 \pm 19.9$ during TI, and $17.6 \pm 20.6$ during TII. Total disappearance of MA was observed in $11.1 \%$ patients during TI and in $42.2 \%$ of patients during T2. No serious adverse event was provoked by Migrasoll ${ }^{\circledR}$ administration. Ginkgolide B is effective in reducing MA frequency and duration. The effect is clearly evident in the first bimester of treatment and is further enhanced during the second.

Keywords Aura - Ginkgolide B - Migraine ·

Platelet activating factor $\cdot$ Prophylaxis

\section{Introduction}

Migraine with aura is characterized by transient and reversible dysfunction of the brain cortex. Visual aura (scotoma and/or fortification spectra), that move across the visual fields, make up the symptomatological counterpart of this cortical anomaly. The aura generally lasts less than one hour and may be followed by the headache attack of migraine or, less frequently, of tension- type headache [1]. The possible cause of the aura is a hyperexcitability of the cortex due to an increase in the amount of excitatory neurotransmitters, i. e. glutamate and aspartic acids, in the synaptic clefts [2].

Although these attacks are usually limited to $2-3$ over the space of a year, no prophylactic treatment is required 
for migraine with aura; at times their frequency increases and a prophylactic treatment is necessary. It is well known that drugs able to modulate glutamate in the central nervous system (CNS), such as lamotrigine, are very effective in preventing aura [3, 4]. However, the side effects and the long time lapse it takes to reach the proper dose limits its use.

Ginkgolide B, a herbal constituent extract from Ginkgo biloba tree leaves, is a natural modulator of the action of glutamate in the CNS [5]. Moreover, it is a potent antiplatelet activating factor (PAF). PAF is a potent proinflammatory and nociceptive agent released during the inflammation process [6]. Indeed, PAF, released from platelets and leukocytes, during the first phase of migraine attack, may sensitize the trigeminal-vascular endings and induce pain $[7,8]$. Therefore, ginkgolide $\mathrm{B}$ may be considered a promising pharmacological aid for the treatment of migraine with aura.

On the basis of this evidence, we assessed the efficacy of ginkgolide B in the treatment of migraine with aura, in a group of patients who complied for at least one aura/month. This was done by an open-label, multicentric study, which investigated into the efficacy of ginkgolide $\mathrm{B}$ in reducing the duration and/or abolishing the number of auras.

\section{Patients and methods}

A total of 50 patients (37 females, 13 males, mean age $36.7 \pm 11.5$ years, range 18-64) suffering from migraine with aura, were enrolled in the study after having obtained written informed consent. The diagnosis was made in agreement with the diagnostic criteria established by the International Classification of Headache Disorders, second edition (ICHD-II) [9] for typical aura with migraine headache $(n=42)$ or typical aura without headache $(n=8)$, The trial lasted six-months.

Inclusion criteria were as follows: age range from 18 to 65 years; a minimum of two years' history of migraine with aura and/or aura without migraine; auras occurring at least once a month; no past or present diseases and, in particular no history of cerebral focal activation; no pregnancy or lactation.

They underwent a two-month run-in period free of prophylactic drugs, followed by a four-month treatment period (subdivided into two bimesters, TI and TII) with a combination of $60 \mathrm{mg}$ ginkgo biloba terpenes phytosome, $11 \mathrm{mg}$ coenzyme Q 10, and $8.7 \mathrm{mg}$ vitamin B2 (Migrasoll $^{\circledR}$ ) administered twice daily. No other migraine prophylaxis was allowed during the study, other than Migrasoll $^{\circledR}$ and within the last month prior to the beginning of the trial; no restriction was placed on analgesic intake. A detailed diary reporting symptoms, duration, and frequency of MA was compiled by patients throughout, and carefully and systematically reviewed during the trial.

The statistical evaluation of aura frequency and duration was performed by an ANOVA test for repeated measures and a post-hoc Bonferroni $t$ test was then applied to localize the source of variance. All analyses were performed by the Statistical Package for the Social Sciences (SPSS) software program (version 15.0). All values given in the following text are reported as arithmetic means $( \pm 1$ SD)

\section{Results}

Of the 50 patients enrolled in the study, five withdrew from the trial; three were due to mild adverse events during treatment (abdominal discomfort $=2$ cases; vertigo $=1$ case) and two were lost to follow-up. The results herein reported are therefore related to the remained 45 patients (34 females, 11 males, mean age $33.6 \pm 10.2$, range 18-64). The run in frequency and duration of aura for each patient are summarized in Table 1.

The attacks frequency decreased significantly from $3.7 \pm 2.2$ in the run-in bimester to $2.0 \pm 1.9$ during the first treatment period and to $1.2 \pm 1.6$ during TII (ANOVA for repeated measures: $P<0.0001$; Bonferroni $t$ test: runin vs. T $\mathrm{I}=P<0.05$; run-in vs. T $\mathrm{II}=P<0.05$; $\mathrm{T}$ I vs. T II $=P<0.05$ ).

There was total disappearance of MA in 5/45 (11.1\%) patients during TI and in 19/45 (42.2\%) patients at the end of treatment period; only five patients were completely unresponsive to treatment (Table 1). Aura duration (expressed in minutes) was markedly reduced throughout the entire treatment course and was $40.4 \pm 19.4$ during the run-in, $28.2 \pm 19.9$ during TI and $17.6 \pm 20.6$ during TII (ANOVA for repeated measures: $P<0.0001$; Bonferroni $t$ test: run-in vs. TI $=P<0.05$; run-in vs. TII $=P<0.05$; T I vs. T II $=P<0.05)$.

Although individual changes in MA symptomatology are not considered in this article, it is noteworthy that there was an overall marked improvement in the neurological symptoms of aura during treatment. Among the patients who completed the study no serious adverse events were reported.

\section{Discussion}

This study shows that Ginkgolide B, contained in the terpenic fraction of Ginkgo Biloba, is effective in reducing both aura frequency and duration in our patient group. The effect is clearly evident in the first two months of treatment and is either maintained, or even further increased during 
Table 1 Frequency and duration of auras in each patient studied
Run-in Bimester of observation before therapy; $T$ I First bimester of therapy; T II Second bimester of therapy; Onset Age at onset of MA; N. auras Total number of auras in the period considered; Duration Total duration of aura symptoms expressed in minutes

\begin{tabular}{|c|c|c|c|c|c|c|c|c|c|}
\hline \multicolumn{4}{|l|}{ PT. } & \multicolumn{2}{|l|}{ Run-in } & \multicolumn{2}{|l|}{ T I } & \multicolumn{2}{|l|}{ T II } \\
\hline $\mathrm{Nr}$ & Sex & Age & Onset & N. auras & Duration & N. auras & Duration & N. auras & Duration \\
\hline 1 & $\mathrm{~F}$ & 41 & 32 & 4 & 60 & 2 & 60 & 2 & 60 \\
\hline 2 & $\mathrm{~F}$ & 27 & 15 & 2 & 55 & 0 & - & 0 & - \\
\hline 3 & $\mathrm{~F}$ & 35 & 6 & 3 & 60 & 1 & 50 & 0 & - \\
\hline 4 & $\mathrm{~F}$ & 26 & 19 & 2 & 45 & 1 & 50 & 1 & 10 \\
\hline 5 & M & 37 & 15 & 4 & 90 & 1 & 70 & 1 & 60 \\
\hline 6 & $\mathrm{~F}$ & 30 & 12 & 2 & 95 & 1 & 50 & 0 & - \\
\hline 7 & $\mathrm{~F}$ & 26 & 20 & 3 & 40 & 2 & 40 & 0 & - \\
\hline 8 & $\mathrm{~F}$ & 18 & 15 & 4 & 25 & 2 & 25 & 1 & 30 \\
\hline 9 & $\mathrm{~F}$ & 25 & 10 & 4 & 40 & 1 & 30 & 2 & 30 \\
\hline 10 & $\mathrm{~F}$ & 39 & 16 & 3 & 50 & 1 & 40 & 1 & 40 \\
\hline 11 & M & 25 & 20 & 3 & 30 & 1 & 10 & 0 & - \\
\hline 12 & $\mathrm{~F}$ & 35 & 25 & 6 & 20 & 6 & 20 & 6 & 20 \\
\hline 13 & M & 46 & 20 & 5 & 25 & 2 & 20 & 0 & - \\
\hline 14 & $\mathrm{~F}$ & 26 & 22 & 2 & 10 & 2 & 10 & 0 & - \\
\hline 15 & $\mathrm{~F}$ & 24 & 19 & 2 & 20 & 0 & - & 0 & - \\
\hline 16 & $\mathrm{M}$ & 33 & 17 & 3 & 45 & 1 & 30 & 1 & 45 \\
\hline 17 & $\mathrm{~F}$ & 34 & 28 & 2 & 65 & 2 & 65 & 1 & 30 \\
\hline 18 & $\mathrm{M}$ & 22 & 18 & 2 & 20 & 0 & - & 0 & - \\
\hline 19 & $\mathrm{M}$ & 23 & 20 & 2 & 15 & 3 & 15 & 3 & 15 \\
\hline 20 & $\mathrm{~F}$ & 64 & 30 & 2 & 20 & 1 & 20 & 0 & - \\
\hline 21 & $\mathrm{~F}$ & 36 & 21 & 2 & 30 & 2 & 15 & 1 & 5 \\
\hline 22 & $\mathrm{M}$ & 48 & 44 & 4 & 35 & 1 & 20 & 0 & - \\
\hline 23 & $\mathrm{~F}$ & 19 & 7 & 8 & 60 & 1 & 15 & 0 & - \\
\hline 24 & $\mathrm{~F}$ & 31 & 14 & 6 & 25 & 3 & 15 & 3 & 15 \\
\hline 25 & $\mathrm{~F}$ & 38 & 20 & 4 & 50 & 3 & 30 & 2 & 15 \\
\hline 26 & $\mathrm{~F}$ & 27 & 24 & 11 & 30 & 5 & 20 & 8 & 10 \\
\hline 27 & $\mathrm{~F}$ & 32 & 12 & 3 & 35 & 1 & 10 & 0 & - \\
\hline 28 & $\mathrm{M}$ & 38 & 29 & 4 & 55 & 3 & 35 & 3 & 35 \\
\hline 29 & $\mathrm{~F}$ & 52 & 27 & 2 & 70 & 1 & 70 & 2 & 70 \\
\hline 30 & $\mathrm{M}$ & 26 & 15 & 3 & 15 & 2 & 10 & 1 & 10 \\
\hline 31 & $\mathrm{~F}$ & 33 & 16 & 2 & 30 & 2 & 40 & 1 & 40 \\
\hline 32 & $\mathrm{~F}$ & 44 & 22 & 4 & 20 & 1 & 20 & 0 & - \\
\hline 33 & $\mathrm{~F}$ & 53 & 16 & 2 & 50 & 2 & 35 & 2 & 40 \\
\hline 34 & $\mathrm{~F}$ & 22 & 11 & 3 & 25 & 1 & 20 & 0 & - \\
\hline 35 & $\mathrm{~F}$ & 45 & 14 & 2 & 40 & 2 & 25 & 1 & 15 \\
\hline 36 & $\mathrm{M}$ & 36 & 13 & 7 & 35 & 8 & 35 & 7 & 35 \\
\hline 37 & $\mathrm{~F}$ & 25 & 11 & 6 & 50 & 4 & 45 & 4 & 30 \\
\hline 38 & $\mathrm{~F}$ & 38 & 31 & 5 & 40 & 1 & 10 & 0 & - \\
\hline 39 & $\mathrm{~F}$ & 23 & 15 & 2 & 50 & 1 & 50 & 1 & 30 \\
\hline 40 & $\mathrm{~F}$ & 39 & 35 & 4 & 30 & 0 & - & 0 & - \\
\hline 41 & $\mathrm{~F}$ & 48 & 18 & 2 & 40 & 2 & 40 & 2 & 40 \\
\hline 42 & $\mathrm{~F}$ & 30 & 22 & 10 & 20 & 8 & 20 & 4 & 5 \\
\hline 43 & $\mathrm{~F}$ & 28 & 18 & 8 & 55 & 6 & 15 & 0 & - \\
\hline 44 & $\mathrm{M}$ & 20 & 15 & 3 & 25 & 0 & - & 0 & - \\
\hline 45 & $\mathrm{~F}$ & 47 & 14 & 5 & 70 & 3 & 70 & 2 & 60 \\
\hline
\end{tabular}


the following two months. It is very unlikely that this positive effect is the primary result of the other components contained in Migrasoll ${ }^{\circledR}$, since Vitamin B2 and Coenzyme Q 10 are present in very low concentrations. Although, to date, the mechanism of action of ginkgolide B on the CNS is still only partially understood, it is believed that the main therapeutical effect may be related to its properties in the modulation of the excitatory function of glutamate in the CNS [10]. Glutamate plays a critical role in initiating and propagating spreading depression (SD), through a stimulation of specific glutamate receptors linked to NMDA channels, and it has been demonstrated that aura is linked to a sudden occurrence of neuronal depolarization and SD on the human cortex $[11,12]$. These neurological phenomena are precipitated when an excessive amount of glutamic and aspartic acids are released from neurons and glia in the synaptic clefts [13]. Indeed, an increased level of these amino acids were found in plasma, platelets, and CSF of migraine with aura sufferers, suggesting that the cortex of these patients may be hyperexcitable [14]. The favorable effect of ginkgolide B in reducing or abolishing the aura in our patients may be due to the modulation and/or reducing the excitatory effect of glutamate in the CNS.

Another important pharmacological property of ginkgolide $\mathrm{B}$ is to hinder the pathological action of PAF, a phospholipid that, under some physiopathological circumstances in the CNS, such as SD, determines a release of glutamic acid into the CNS, contributing to its hyperexcitability [15]. A further beneficial effect of ginkgolide B in migraine patients may be its activity against the formation and the deposition of free radicals in the CNS [16, 17]. Indeed, recent evidence suggests that the high frequency of migraine attacks is associated to an abnormal amount of free radicals present in the CNS [18]. The inhibition of free radical production and deposition may reduce the recurrence of the aura.

Our preliminary study indicates that Migrasoll ${ }^{\circledR}$ is a safe product, that can be used routinely to reduce both MA frequency and length, with only minor possible side effects. Nevertheless, even if our preliminary data are encouraging, as this is an open study, it should be interpreted with caution and confirmed by larger placebo controlled studies and longer follow-up periods.

Conflicts of interest statement Giovanni D'Andrea is a consultant and is on the speaker's bureau of Pharmaval Srl, Italy.

Open Access This article is distributed under the terms of the Creative Commons Attribution Noncommercial License which permits any noncommercial use, distribution, and reproduction in any medium, provided the original author(s) and source are credited.

\section{References}

1. D’Andrea G, Bonavita V, Rigamonti A, Bussone G (2003) Treatment of migraine with aura: comment and prospectives. Neurol Sci 23:271-278

2. Welch KMA, D'Andrea G, Tepley N, Barkley GL, Ramadan NM (1990) The concept of migraine as a state of central neuronal hyperexcitability. Neurol Cin 8:817-828

3. D'Andrea G, Granella F, Cadaldini M, Manzoni GC (1999) Effectiveness of lamotrigine in the prophylaxis of migraine with aura: an open pilot study. Cephalalgia 19:64-66

4. Lampl C, Katsarava Z, Diener HC, Limmroth V (2006) Lamotrigine reduces migraine with aura attacks in patients with migraine with aura. J Neurol Neurosurg Psychiatry 76:1730-1732

5. Williams B, Watanabe CMH, Schultz PG, Rimbach G, Kruker T (2004) Age-related effects of Ginkgo Biloba extract on synaptic plasticity and excitability. Neurobiol Aging 25:955-962

6. Akisu M, Kultursay N, Coker I, Huseyinov A (1998) Plateletactivating factor is an important mediator in hypoxic ischemic brain injury in the newborn rat. Flunarizine and Ginkgo Biloba extracts reduce PAF concentration in the brain. Biol Neonate 74(6):439-444

7. D'Andrea G, Hasselmark L, Alecci M, Cananzi A, Perini F, Welch KMA (1994) Platelet secretion from dense and $\alpha$-granules in vitro in migraine with or without aura. J Neurol Neurosug Psychiatry 57(5):557-561

8. Sarchielli P, Alberti A, Coppola F, Baldi A, Gallai B, Floridi A, Capecchi G, Gallai V (2004) Platelet-activating factor (PAF) in internal jugular venous blood of migraine without aura patients assessed during migraine attacks. Cephalalgia 24:623-630

9. The international classification of headache disorders, 2 nd edn (2004) Cephalalgia 24 (suppl 1):1-160

10. Bryn W, Coran MH, Coran MH, Schultz PG, Rimbach G, Krucker T (2004) Age-related effect of Ginkgo Biloba on synaptic plasticity and excitability. Neurobiol Aging 25:955-962

11. Cananzi AR, D’Andrea G, Perini F, Zamberlan F, Welch KMA (1995) Platelet and plasma levels of glutamate and glutamine in migraine with and without aura. Cephalalgia 15:132-135

12. Bowyer SM, Aurora KS, Moran JE, Tepley N, Welch KMA (2001) Magnetoencephalografic fields from patients with spontaneous and induced migraine aura. Ann Neurol 50:582-587

13. Waltkins JC, Jane ED (2006) The glutamate story. Br J Pharmacol 147(S1):S100-108

14. D'Andrea G, Cananzi AR, Joseph R, Morra M, Zamberlan F, Ferro Milone F, Grunfeld S, Welch KMA (1991) Platelet glycine, glutamate and aspartate in primary headache. Cephalalgia 11:197-200

15. Nogami K, Hirashima Y, Endo S, Takaku A (1997) Involvement of platelet-activating factor (PAF) in glutamate neurotoxicity in rat neuronal cultures. Brain Reseach 754:72-78

16. Pincemail J, Deby C (1986) Propietés antiradicalaires de l'extrait de Ginkgo Biloba. Presse Medicale 15:1475-1479

17. Droy-Lefaix MT, Doly M (1992) EGb 761, a retinal free-radical scavenger. In: Christen Y, Constantin J, Lacour M (eds) Effect of Ginkgo Biloba Extract (EGb 761) and central nervous system. Elsevier, Paris

18. Welch KMA (2003) Contemporary concepts of migraine pathogenesis. Neurology 61:S2-S8 